\title{
Parents, Peers, and Politics: The Long-term Effects of Vertical Social Ties
}

\author{
Linuz Aggeborn ${ }^{1}$, Nazita Lajevardi ${ }^{2}$, Karl-Oskar Lindgren ${ }^{3}$, Pär Nyman ${ }^{4}$ and \\ Sven Oskarsson ${ }^{5 *}$ \\ ${ }^{1}$ Uppsala University, Sweden; linuz.aggeborn@statsvet.uu.se \\ ${ }^{2}$ Michigan State University, East Lansing, MI, USA; nazita@msu.edu \\ ${ }^{3}$ Uppsala University, Sweden; Karl-Oskar.Lindgren@statsvet.uu.se \\ ${ }^{4}$ Uppsala University, Sweden; par.nyman@statsvet.uu.se \\ ${ }^{5}$ Uppsala University, Sweden; Sven.Oskarsson@statsvet.uu.se
}

\begin{abstract}
We examine how one's adult political participation is affected by having social ties to a politician during adolescence. Specifically, we estimate the long-term effect of having had a classmate during upper secondary school whose parent was running for office on future voter turnout and the likelihood of running for and winning political office. We use unique Swedish population-wide administrative data and find that students in school classes with a larger number of politically active parents are more politically active as adults, both in terms of voting and political candidacy. Our results suggest that the effect of vertical social ties is predominantly mediated
\end{abstract}

*We thank seminar participants at Uppsala University, the Oslo Turnout Workshop (2017), Swepsa (2017), APSA (2018), and MPSA (2019) for their helpful and constructive comments. Earlier versions of this paper circulated under the titles "Do Political Acquintances Make You Politically Active?" and "The Effect of Having Peers Whose Parents Are Politicians." This research was funded by the European Research Council (ERC), grant number 683214 CONPOL, and the Swedish Research Council (VR), grant number 2017-02472.

**Although the QJPS is committed to making replication material available, this article makes use of sensitive data that cannot be publicly shared. The associated replication file contains the code needed for scholars with access to the data to fully replicate the reported result.

\footnotetext{
Online Appendix available from:

http://dx.doi.org/10.1561/100.00019057_app

Supplementary Material available from:

http://dx.doi.org/10.1561/100.00019057_supp

MS submitted on 8 April 2019; final version received 28 November 2019

ISSN 1554-0626; DOI 10.1561/100.00019057

(C) 2020 L. Aggeborn, N. Lajevardi, K-O. Lindgren, P. Nyman and S. Oskarsson
} 
by indirect links between the politician and the student via the children of politicians. Moreover, we show that the strength of these mobilizing effects depends on the individual's basic predisposition to engage in different types of political activities.

Keywords: Political participation; vertical ties; Sweden

Spurred by the great boom of research on social capital (Putnam, 2000; Putnam et al., 1993), the last few decades have witnessed an increase in scholarly interest in the social dimensions of politics (Campbell, 2013; McClurg, 2003; Rolfe, 2012; Zuckerman, 2005). The basic intuition motivating this perspective is that citizens' decisions to participate in politics are not formed in a vacuum, but rather depend on their social surroundings (Lazarsfeld et al., 1944). The study of social networks, thus, has become integral to understanding why individuals choose to exercise democratic rights, such as voting or running for political office.

Yet, research so far has primarily assessed horizontal social networks evaluating, for instance, how discussing politics with one's peers impacts one's political behavior and attitudes (Huckfeldt and Sprague, 1995; Kenny, 1992; Klofstad, 2007; La Due Lake and Huckfeldt, 1998; McClurg, 2003; Mutz, 2002). As Smith (2016) notes, relatively less attention has been paid to empirically assessing the importance of vertical social ties for connecting citizens to their elected representatives.

From a theoretical point of view, this state of affairs is somewhat surprising because it has long been assumed that proximity to politicians increases citizens' political involvement. In its modern form, this argument can be traced back to Dahl and Tufte's (1973) seminal contribution on the relationship between size and democracy. One important reason citizens in smaller political units tend to be more politically active, they argue, is that individuals are more likely to both "know officials names and have attitudes about them" compared to those residing in larger political units (Dahl and Tufte, 1973, p. 64). In line with this reasoning, Lassen and Serritzlew (2011) find that internal political efficacy among citizens declined as Danish municipalities were merged into larger units. A partial explanation for this, they offer, is that the reform made it less likely for citizens to have local politicians in their social networks (Lassen and Serritzlew, 2011, p. 4). Notwithstanding the plausibility of these arguments, systematic studies on the importance of vertical social ties in shaping political participation are largely lacking.

Although the lack of research on the participatory effects of social connections to politicians is surprising on theoretical grounds, it is more understandable from a methodological perspective. One challenge concerns access 
to relational data. Studying how social ties to elected officials affect political participation ideally requires information on whether an individual is personally acquainted with a politician, which is rarely asked in surveys on political participation. And, even when available, the number of respondents with social ties to politicians is usually too small to allow for sufficient precision in the estimation of the effect of interest.

One additional limitation stems from the group of citizens who know a politician being unlikely to constitute a random subset of the entire population. On the contrary, we can safely assume that a set of important observed and unobserved factors confound any correlation between connections to politicians and political engagement. In order to argue that differences in political activity between those who know a politician and those who do not actually reflects a causal effect of vertical ties, we must employ more sophisticated identification strategies to account for potential confounders. Achieving this is always very difficult, but particularly so when working with small random samples.

We overcome these challenges by using unique Swedish population-wide administrative data to examine how having social ties to a politician during adolescence affects one's adult political participation. More specifically, we estimate how having had a classmate during upper secondary school whose parent was running for office at that time affects one's voter turnout and one's likelihood of running for and winning political office later in life.

We focus on the school context for both theoretical and methodological reasons. Theoretically, previous research has pointed to schools as one of the most important arenas for political socialization (Neundorf and Smets, 2017). To take but a few examples, adult political engagement has been shown to be higher among those who participate in school politics (Fox and Lawless, 2005), discuss politics in class (Campbell, 2008), and participate in youth civil associations and extracurricular activities (Beck and Jennings, 1982; Hanks, 1981; McFarland and Thomas, 2006; Smith, 1999; Verba et al., 1995).

Many of these studies highlight the relevance of peer socialization. Children attending school together interact with one another both inside and outside of the classroom, and are thus likely to influence each other's political development (Campbell, 2008; Kudrnáč and Lyons, 2017). However, as Putnam (2015, p. 166) reminds us, an additional reason why it matters who you go to school with is that students tend to "bring their parents with them to school," at least figuratively speaking. Just as students' own parents may be of importance for adolescent development, so may the parents of their friends and schoolmates. For instance, some studies indicate that individuals who are exposed to peers whose parents are well educated are more likely to become well educated themselves. The reason for this, it is argued, is that schoolmates' parents can act as providers of educational information and connections and serve as inspirational role models for the friends of their children (Cherng et al., 2013; Choi et al., 2008). One important contribution of the present study 
is to examine whether this argument also applies to the case of political participation.

With this being said, there are also methodological reasons for studying the importance of social networks within the school setting. Most importantly, we use the fact that two individuals living in the same place are much more likely to be in the same class and spend time together if they are born in the same year. In this study, we attempt to handle the selection problems inherent in any study of the effects of social bonds by comparing students who went to the same school and attended the same educational program, but were placed in different classes with different sets of classmates because they were enrolled in different years. Under the assumption, for which we later argue, that the year-to-year variation in the number of politicians among the parents across similar school classes is "as good as random," this comparison enables us to estimate the causal effect of being socially linked to a politician through one's classmates.

This study has important implications for both research and policy. Academically, the study contributes to our understanding of the role of weak social ties in the process of adolescent political socialization. Following the seminal work of Granovetter (1973), strong social ties denote the social bonds to close family and friends, whereas weak social ties refer to the relationship maintained with more distant acquaintances, such as a friend of a friend, or as here, the parent of a friend. Traditionally, political socialization research has focused on the impact of strong social ties on adolescent political development, while that of weak social ties has largely been neglected. One important contribution of the present study lies in its attempt to address this imbalance by examining whether children with weak social ties to active politicians are more likely to become politically active themselves.

In doing so, the study could also be of significant practical value. The study underscores that if we want to understand, and ultimately alleviate, the high levels of political inequality plaguing many developed democracies, we may have to take the diversity of social networks into account. If both strong and weak social ties help to shape adolescent political development, children from affluent backgrounds are doubly advantaged compared to those from less privileged homes.

Because political activity is associated with socioeconomic status, better off children are likely to have more politically engaged parents, which increases the likelihood that children will engage in politics themselves as adults. Moreover, due to school and residential segregation, socioeconomically advantaged children are considerably more likely to maintain weak social ties to politicians and other politically active citizens, which could further bolster their political participation.

The prestigious elite schools that exists in many developed democracies, and which have long served as key training grounds for future political leaders, 
can be used to illustrate this point. Perhaps the extraordinary political success of graduates from schools such as Eton, SciencesPo or ENA is not only due to their own family backgrounds, but also because attendance at these schools provides students with weak social ties to a large set of influential politicians and policy-makers. To the extent that this is the case, alleviating class-based school segregation could also help to reduce overall political inequality.

To preview our results, we find that having social ties to a politician while attending upper secondary school has important long-term effects on an individual's later political participation. We find that every extra upper secondary school classmate whose parent is a politician results in an increase in voting propensity later in life. We also find that having one extra politician parent in the class results in a four percent higher probability of ever running for office as an adult, although this latter outcome should be interpreted with some caution given that few individuals actually ever run for political office. We extend this analysis and find that the strength of the effect depends on an individual's nascent propensity to be politically active and that it is primarily channeled via the bonds formed between the politician's child and their classmates, rather than through direct links between the politician parents and the students.

\section{Why Should Vertical Ties Increase Political Activity?}

To repeat the famous recommendation from Verba et al. (1995), when attempting to explain why some individuals participate more in politics than others it is often more productive to turn the question around and ask why people do not take part in politics. Three main explanations immediately come to the authors' minds: "because they can't; because they don't want to; or because nobody asked" (Verba et al., 1995, p. 14). Extending this line of thinking, when we consider why being in proximity to a politician may matter for political activity, it is fruitful to structure the discussion around these different explanations.

Starting with the "can't" explanation, the main reason why citizens feel they cannot participate in politics is that they lack the necessary resources in terms of time, money, and skills (Verba et al., 1995, p. 271). In well-functioning democracies we should not expect that merely knowing a politician will have an effect on resources such as time and money; it is much more natural to conceive of how this relationship could impact civic skills. In particular, it seems likely that social ties to political officials can make citizens more aware of and knowledgeable about politics. Knowing a politician can make a person aware of ongoing issues in politics and provide them with the tools to process and take a position on these matters. 
A second reason for not participating in politics is that citizens "don't want to" because they lack psychological engagement with politics (Verba et al., 1995, p. 269). The literature on descriptive representation presents a starting point for hypothesizing how this mechanism may mediate a relationship between vertical social ties to politicians and participation. An important argument in this literature is that the presence of visible political role models can enhance political interest and efficacy among politically marginalized groups. Numerous studies have shown that the presence of women or ethnic minorities in important political roles may make members of these groups more interested in politics (Barreto, 2007; Campbell and Wolbrecht, 2006; McConnaughy et al., 2010; Shah, 2014) and, in turn, induce them to experience that they are capable of affecting political outcomes (Gilardi, 2015; Wolbrecht and Campbell, 2007). Similarly, having a peer during adolescence whose parent is a politician may also affect an individual's future political participation by increasing his or her psychological engagement with politics. Interactions with a politician and their child can make a student more observant to political matters and can also increase the feeling that participation is important for the functioning of the democracy.

A third way in which social networks can affect participation is through recruitment or by "being asked" (Teorell, 2003; Verba et al., 1995, p. 273). Citizens who personally know a politician may be more politically active because they are more likely to receive requests for participation in various types of political events or activities. Turning once again to the literature on gender and race and ethnic politics, there is ample evidence that women and minorities do not turn out at higher rates because no one asked (e.g., see Barreto and Nuño (2011) and Fox and Lawless (2005)). Receiving encouragement to participate in politics can provide individuals with a sense of belonging to the political process, which in turn can increase their propensity to be politically active (Ocampo, 2018).

It is important to note here that there are at least three different linkages through which having a classmate whose parent is a politician can increase one's political participation. A first possibility is that students are influenced directly by the politician parent. Parents have been shown to be socializing agents of motivation and engagement for their own children (Rubin et al., 2008). Given that politician parents may be interacting with their children's classmates, they may have an impact on those students as well. For example, political socialization might occur through political discussions when visiting the home of a classmate whose parent is a politician. It is also possible that the politician parent comes to class to speak about their life as a politician. The second possibility is that the acquisition of political knowledge and interest or the request to engage in politics is mediated by the child of the politician. The education literature highlights the importance of peer groups in socializing motivation and achievement (Berndt et al., 1990; Robnett and Leaper, 2013; 
Rubin et al., 2008; Ryan, 2000). Here, students might learn about and develop an interest in politics from their classmates when they have discussions in the school context. A third possibility is that the effect goes through the parents who themselves are not politicians. In this case, the parents are influenced by having a child in a class where there are politicians and these parents later become politicians themselves. The transmission to the child in such a case would be an intergenerational transmission taking place after upper secondary school, and one that is initialized by a parent-to-parent influence during upper secondary school. ${ }^{1}$

Finally, it seems likely that the effect of vertical social ties to politicians on individuals' political participation depends on their underlying tendency to be politically active citizens. Drawing on Fox and Lawless's (2005) influential work on nascent political ambition, we may differentiate between factors that influence an individual's inclination to engage in a certain political act (e.g., voting in an election or running for office) and factors that may push or pull someone into actually expressing this underlying ambition. The former factors involve, among other things, innate predispositions (Cesarini et al., 2014; Dawes et al., 2014; Fowler et al., 2008; Oskarsson et al., 2018) and early life socialization (Beck and Jennings, 1982; Jennings, 2007; Lawless, 2011), whereas the latter factors are more proximate in nature, for example having social connections to active politicians.

Given this simple framework, we should expect those individuals with either very high or very low underlying propensities to act politically to be less influenced by having social ties to political officials. In both cases, it probably takes more than the rather modest stimulus provided by the presence of active politicians in one's social network to spur any changes in already firmly grounded political (in)activity. On the other hand, for individuals who are more indifferent between acting or abstaining, such social ties may be decisive for turning nascent tendencies into actual behavior.

An important empirical implication of this line of argument is that the effect of social ties may differ across groups and the type of participatory act being studied. For demanding, costly, and competitive political acts that very few perform, such as running for office, social connections to active politicians should mainly affect those individuals with a relatively high predisposition to engage in politics, such as those from more affluent and politicized family backgrounds. For less demanding and more common political acts, such as voting in first order elections, we instead expect such social ties to be of greater importance for individuals with a relatively lower predisposition towards the act in question.

\footnotetext{
${ }^{1} \mathrm{~A}$ fourth, and less likely mechanism is that parents who are not politicians later run for office because they have children in a class where there are politician parents, but the mechanism is mediated instead by the students in the class.
} 
As this discussion indicates, there are a number of reasons for why having social ties to a politician can impact citizens' political participation and why an average effect of such connections may conceal important heterogeneities. Based on the impressionable years model advanced by scholars of political socialization, we may further expect these effects to be particularly pronounced in the period prior to adulthood when individuals are more politically malleable (e.g., Jennings, 2007; Stoker and Bass, 2011). However, as discussed in the introduction, both scarcity of appropriate data and methodological challenges have led to a relative lack of firm knowledge about the downstream effects on adult political participation of social ties to active politicians during adolescence. In the remaining parts of this study, we set out to shed more empirical light on this central and underexplored question.

\section{Empirical Framework}

Before moving to our identification strategy, we offer a brief primer on the Swedish upper secondary school system. Swedish students enter the upper secondary school system after nine years of compulsory schooling, which usually coincides with the year they reach the age of 16. Although upper secondary school is voluntary in Sweden, a large majority of all students attend the three-year long programs, making it a large and important part of the Swedish education system (SCB, 2018).

Students apply to upper secondary school in the spring semester of the last (ninth) year in elementary school. At the time of application, students can choose which school to attend and which program to enter into within that school. Students in upper secondary school enroll in 1 of 16 national educational programs where the programs are divided into two groups: programs that prepare students to attend university (e.g., natural science and social science programs) and vocational programs (e.g., industry and construction programs).

For ease of interpretation, we refer to a single cohort attending a specific program at a specific school as a class. We note, however, that in larger upper secondary schools certain educational programs are divided into several classes. Students who are enrolled in a specific program are often instructed together, but they can also be divided into smaller groups for some subjects.

Given that students apply to upper secondary school based on their interests and their GPA from ninth grade, there is a great deal of self-selection into educational programs and into specific schools. For this reason, a simple comparison of political participation among students who were enrolled in a class where there were many politician parents to those students who attended a class where there were few or no politician parents would not yield a causal 
effect. It is likely that students whose parents are politicians are more interested in politics and that they overall perform better in school. As a result, it is possible that they self-select into certain schools and certain programs when they apply to upper secondary school. Other students in those programs are also likely to have higher cognitive abilities and higher SES status, which we in turn expect to have positive effects on political participation. Because students are not randomly assigned to upper secondary schools and to particular programs within those schools, we are unable to separate the causal effect from such selection bias without a proper identification strategy.

We employ a strategy in which we compare students from different cohorts who attended the same upper secondary school and the same program within that school to one another. Our treatment can only vary over the different cohorts. Our identification strategy thus assumes that it is as if random which specific cohort a person belongs to for a given upper secondary school and for a given program within that school. Because education in upper secondary school is organized around each cohort separately, students spend most of their time together with other students of the same age, and as such, we should not expect any notable effects from politically engaged parents in other cohorts. We estimate the following regression equation in the main analysis:

$$
Y_{i s p c}=b_{0}+b_{1} X_{s p c}+b_{2} W_{i s p c}+b_{3} W_{i s p c}^{p}+\delta_{c}+f_{s p}+e_{i s p c},
$$

where $Y_{i s p c}$ is a dichotomous indicator of the participatory act (voter turnout, running for office or winning office) for individual $i$ in school $s$, attending program $p$, and belonging to cohort $c$. We define the outcome variables as either 0 or 100 to simplify interpretation. $X_{s p c}$ denotes the number of parents in a particular class $s p c$ that was running for office in an election just prior to or during the time the child attended upper secondary school. The model also includes a set of control variables. $W_{i s p c}$ is a vector of individual controls including gender and immigrant status. $W_{i s p c}^{p}$ is a vector of family (parental) characteristics including information on income, education, employment, and welfare recipient status of an individual's father and mother, respectively. The vector $W_{i s p c}^{p}$ also includes the average of the same variables for all parents of a particular class. $b_{0}$ is the intercept and $e_{i s p c}$ is the error term.

Most importantly for identification, we include a set of fixed effects where $f_{s p}$ are unique indicators for each school-program combination. We also add separate cohort fixed effects $\left(\delta_{c}\right){ }^{2}$ The standard errors are clustered at the same level as the fixed effects: the school-program level.

\footnotetext{
${ }^{2}$ In some models we also enter municipal fixed effects for the municipality of residence in 2009. We choose 2009 because this is the year of measurement for our first outcome variable.
} 


\section{Data and Descriptives}

We construct our dataset by merging data from several administrative sources maintained at Statistics Sweden. The sample consists of all students who, according to the school application records, started upper secondary school between 1994 and 2007, implying that they completed upper secondary school between 1997 and $2010(N=1,371,539) .{ }^{3}$ After dropping students whose program codes are undefined, we are left with 1,269,429 individuals. Next, we restrict the sample to individuals attending upper secondary school classes containing equal to or more than five students $(N=1,264,746)$. Using the Multi-Generation Registry, we match these individuals with their parents. We also drop all students whose parents are active politicians and focus the entire empirical analyses on the spill-over effects to other students in a class because we are not interested in the intergenerational effect of having a parent who is a politician $(N=1,226,245){ }^{4}$

These individuals and their parents are then matched with various administrative registers containing information on a range of demographic and socioeconomic characteristics as well as indicators of political participation. To construct our main independent variable, the number of politically active parents per class, we combine information from school registers with information on political candidacy from the Register of Nominated and Elected Candidates which contains records of all candidates in the municipal, county, and national elections held between 1982 and 2014. ${ }^{5}$

As discussed in the previous section, we define a school class as students beginning upper secondary school in a specific year and attending the same program at the same school. Defined in this way, the number of students in a class is on average 37.9 (s.d. $=37.0 ; \max =394$ ). Figure 1 (a) shows that the number of students for a given school, a given program, and a given cohort has fluctuated somewhat over time. Meanwhile, Figure 1(b) displays a histogram of the number of students per school class. Although our procedure to identify classmates through unique school-program-cohort combinations works very well in most cases, it gives rise to very large student groups in some instances. We examine how the estimates are affected by restricting the sample to smaller classes in the robustness section.

${ }^{3} \mathrm{~A}$ reform in 1994 changed the upper secondary school system in Sweden. Prior to the reform, upper secondary school consisted of different educational tracks. After the reform, 16 national programs were instead introduced making it difficult to compare cohorts graduating before and after 1997. As a result, our entire empirical analyses is focused on individuals graduating 1997 or later.

${ }^{4}$ There are some few duplicates in the registry data and these individuals have been dropped. There are also some missing values for some of the variables used in the analysis.

${ }^{5}$ All three elections - the national and the two regional (county- and municipal-level) elections - are held simultaneously in September every three (until 1994) or four (after 1994) years. 


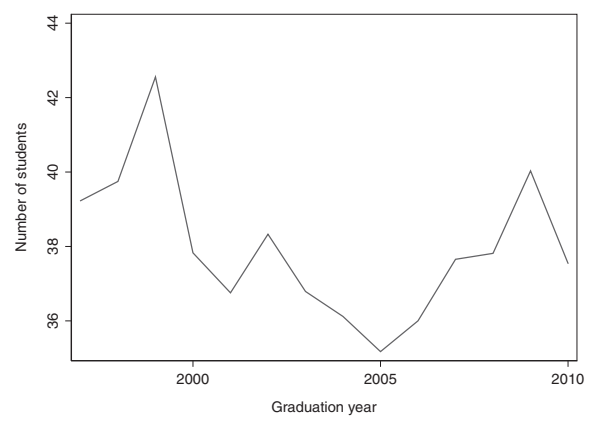

(a)

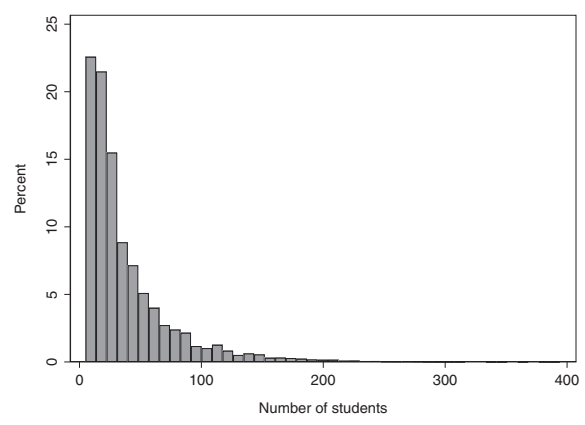

(b)

Figure 1: The distribution of class size. (a) Average class size by graduation year. (b) Distribution of class size.

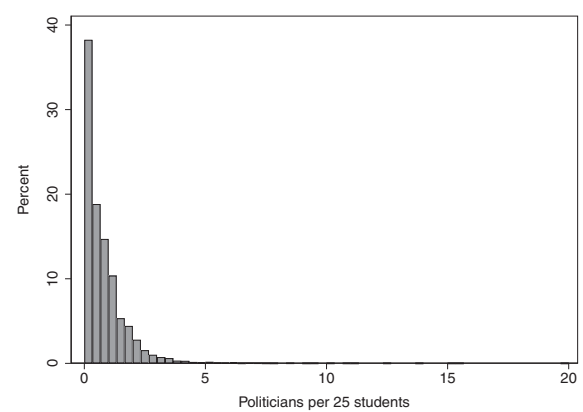

(a)

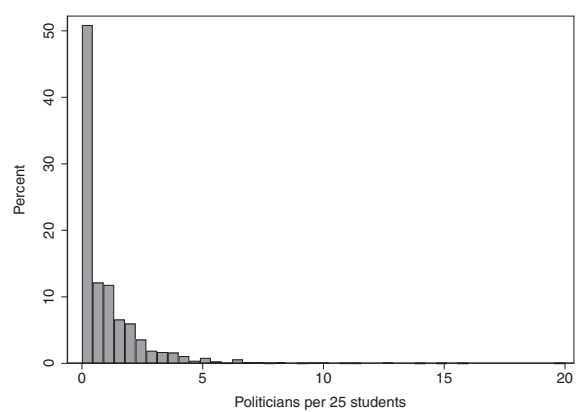

(b)

Figure 2: Distribution of politically active parents per 25 students. (a) Individuals. (b) Classes.

Next, we calculate the number of politically active parents per class. We define as politically active all parents who ran for office in the election occurring just prior to or during the time the child attended upper secondary school. To make the measure comparable across classes of different sizes, we express the variable as the number of politically active parents per 25 students which corresponds to what we consider to be a normal sized class. Figure 2 depicts the distribution of this variable using either individuals (panel (a)) or classes (panel (b)) as the unit of analysis. About half of the classes have at least one politician among the parents in the class. Some rare classes have extremely large numbers of politician parents, but only $1 \%$ of individuals have more than 4 politician parents per 25 students in their class. The mean is 0.75 politicians when the unit of analysis is individuals. 
Turning to our outcome measures, we rely on four variables to capture mass and elite political participation. We measure mass political participation as voter turnout. Unfortunately, the public registers do not contain validated population-wide turnout information. Instead, we take advantage of a recent effort of ours to collect population data on voter turnout in the 2009 European parliament election and the 2010 general election. ${ }^{6}$ By scanning and digitizing information in the publicly available election rolls, we were able to retrieve validated voter turnout information for approximately 7,000,000 individuals (amounting to almost 95\% of the total electorate). The individual-level voter turnout data resulting from this undertaking is unique both in terms of number of observations and data accuracy. ${ }^{7}$

Elite participation is measured through two dummy indicators for having run for and won elected office at least once in the five elections between 1998 and 2014. These indicators are derived from information contained in the Register of Nominated and Elected Candidates. ${ }^{8}$ It should be noted that the vast majority of the total number of nominated and elected candidates in our estimation sample consists of individuals running for and winning office at the municipality level. Municipalities in Sweden are important entities within the political system and are responsible for a large share of total public spending. Elections to municipal councils and selection to the municipal board function similarly to elections to the national parliament and selection to the national government. Municipal councils are elected using a party-list proportional system and the municipalities are governed by a "quasi-parliamentary system" where a majority party or coalition appoints committee leaders and sets the municipality's policies (Bäck, 2003). It is also important to note that municipalities have the right to decide on income taxation independently of the central government. In addition, municipalities in Sweden provide important government goods and services, such as education and social assistance, and they function as important public employers.

\footnotetext{
${ }^{6}$ Turnout levels in Swedish general elections are high in a comparative perspective. For example, the overall turnout rate in the 2010 parliamentary election was $84.6 \%$. However, turnout levels in the elections to the European parliament are considerably lower. In the $2009 \mathrm{EP}$ election $45.5 \%$ of the electorate made use of their right to vote.

${ }^{7}$ Lindgren et al. (2019) provide a detailed description of the procedures used to scan and digitize these election rolls. Extensive quality checks suggest that the digitized information on electoral participation conforms with actual voting behavior in at least $99.7 \%$ of the cases.

${ }^{8}$ More precisely, these measures are based on the five elections held between 1998 and 2014 in which the individuals were eligible to run for office. This means that individuals in the two oldest cohorts in the sample had the possibility to run for office in all five elections whereas the youngest cohorts could only run in the two most recent elections in 2010 and 2014. Note that in some cases, individuals may be eligible to run for office during upper secondary school if they are over age 18 .
} 


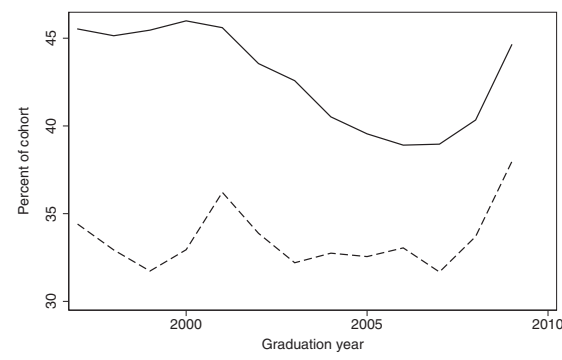

- - - - No parent pol. _— At least 1 parent pol.

(a)

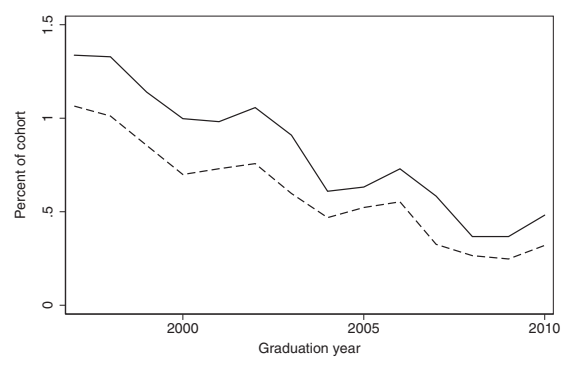

(c)

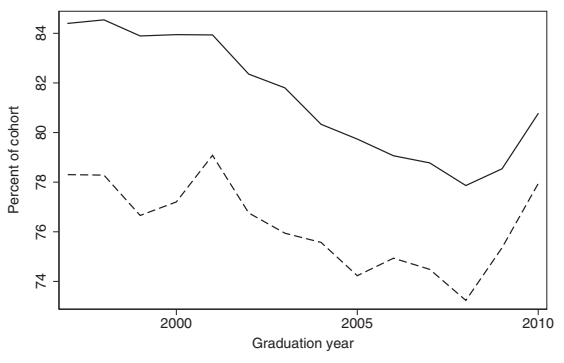

---- No parent pol. _— At least 1 parent pol.

(b)

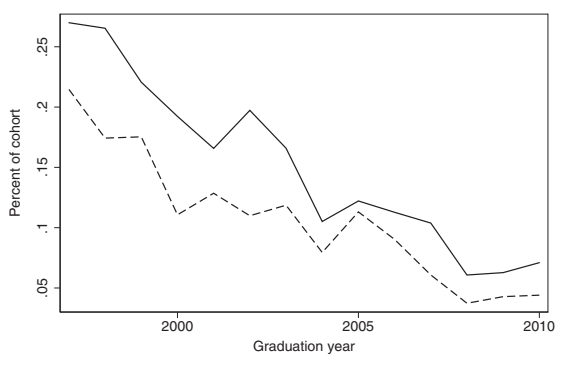

(d)

Figure 3: Political participation by cohort and parental political activity. (a) Voter turnout EP 2009. (b) Voter turnout general election 2010. (c) Share who ran for office. (d) Share who were elected.

Finally, we match individuals in the sample and their parents to various administrative registers with information on educational attainment, income, occupational status, and some additional demographic and socioeconomic characteristics. ${ }^{9}$

Figure 3 presents initial descriptive evidence on the association between vertical social ties to politicians and our four outcomes. The four panels display the mean level (in percentage points) of each participatory act across the cohorts graduating between 1997 and 2010, for those who had at least one classmate whose parent was a politician (solid line) and also for those who had no classmates whose parents were politicians (dashed line). As expected, we observe large variation in the baseline probability of carrying out these different political acts.

Turning first to the association between age and political participation, there is a non-linear relationship between birth cohort and voter turnout,

\footnotetext{
${ }^{9}$ See the Online Appendix for additional information on these registers and the variables included in the final data set.
} 
especially for the European parliament election. This pattern of results corroborates the findings presented in Bhatti et al. (2012) and suggests that turnout levels decline during the first years of eligibility and recover only when the voters reach their late twenties. Unsurprisingly, the probability of being either nominated or elected is approximately linearly increasing in age.

More interestingly for our purposes, however, is the positive relationship between our treatment variable and all four outcome indicators. Having attended an upper secondary class in which at least one of the classmates had a parent who was a politician is associated with a considerably higher likelihood of both mass and elite political participation as a young adult. However, as already discussed, an obvious problem here is that the number of politically active parents among the children of a class is bound to be correlated with other important determinants of political activity.

Table 1 explores whether this is in fact the case by presenting some basic descriptive statistics separately for the whole sample (Column 1) and for individuals attending classes without any (Column 2) and with at least one (Column 3) politician parent. Once again we can see that there are clear

Table 1: Descriptive statistics.

\begin{tabular}{lccc}
\hline Variable & Full sample & No politician & At least one \\
\hline Turnout 2009 & 38.76 & 32.33 & 41.52 \\
Turnout 2010 & 79.81 & 76.14 & 81.39 \\
Ever nominated & 0.74 & 0.55 & 0.82 \\
Ever elected & 0.13 & 0.10 & 0.15 \\
Parent politicians per 25 students & 0.76 & 0.00 & 1.09 \\
Woman & 0.49 & 0.45 & 0.51 \\
Foreign born & 0.08 & 0.09 & 0.08 \\
Years of education, father & 12.25 & 11.81 & 12.44 \\
Years of education, mother & 12.62 & 12.21 & 12.80 \\
Standardized income, father & 0.78 & 0.66 & 0.83 \\
Standardized income, mother & 0.33 & 0.27 & 0.36 \\
Social assistance recipient, father & 0.06 & 0.07 & 0.05 \\
Social assistance recipient, mother & 0.08 & 0.10 & 0.07 \\
Father employed & 0.86 & 0.84 & 0.87 \\
Mother employed & 0.85 & 0.83 & 0.86 \\
Observations (min) & 1177572 & 351666 & 825906 \\
Observations (max) & 1264746 & 380033 & 884713 \\
\hline
\end{tabular}

Note: The table shows the average values of our key variables for the full sample (Column 1), those who had no politicians among the parents in the class (Column 2), and those who had at least one politician parent (Column 3). 
bivariate relationships between vertical social ties to active politicians and the four measures of political participation. However, comparing across Columns 2 and 3 , it is also evident that the two groups are rather different in terms of background characteristics. As expected, students in classes in which at least one of the parents is an active politician are positively selected compared with students lacking these social ties. Above all, their parents are more highly educated and more often employed, have higher incomes, and are less likely to be social assistance recipients. These differences highlight the need for a proper identification strategy in order to credibly estimate the causal impact of vertical social ties on political participation. This is the focus of the next section of the paper.

\section{Baseline Results}

How is adult participation affected by having had peers during upper secondary school whose parents are politicians? The results for voter turnout and elite participation are presented in Tables 2 and 3, respectively. The structure of both tables is the same for all outcomes; the first column displays results from a simpler specification and the two subsequent columns contain estimates from models in which we sequentially add more covariates and fixed effects. The last

Table 2: Voter turnout.

\begin{tabular}{lcccccc}
\hline & $(1)$ & $(2)$ & $(3)$ & $(4)$ & $(5)$ & $(6)$ \\
& Vote09 & Vote09 & Vote09 & Vote10 & Vote10 & Vote10 \\
\hline $\begin{array}{l}\text { Number of } \\
\text { politicians }\end{array}$ & 0.328 & 0.279 & 0.294 & 0.122 & 0.089 & 0.105 \\
\hline $\begin{array}{l}\text { Mean } \\
\quad \text { dep.var. }\end{array}$ & 39.466 & 40.088 & 40.815 & 79.577 & 80.271 & 81.256 \\
$\begin{array}{l}\text { Individual } \\
\quad \text { covariates }\end{array}$ & Yes & Yes & Yes & Yes & Yes & Yes \\
$\begin{array}{l}\text { Parent } \\
\quad \text { covariates }\end{array}$ & No & Yes & Yes & No & Yes & Yes \\
$\begin{array}{l}\text { Cohort FE } \\
\text { Muni. FE }\end{array}$ & Yes & Yes & Yes & Yes & Yes & Yes \\
$\begin{array}{l}\text { Adjusted } R^{2} \\
\text { Observations }\end{array}$ & 0.078 & 0.093 & 0.118 & 0.065 & 0.070 & 0.135 \\
\hline
\end{tabular}

Note: Results from OLS regressions. The outcome in Columns 1-3 is turnout in the 2009 EP election whereas estimates for turnout in the 2010 national election are presented in Columns 4-6. Standard errors, shown in parentheses, allow for clustering at the school-program level. 
Table 3: Elite political participation.

\begin{tabular}{|c|c|c|c|c|c|c|}
\hline & (1) & $(2)$ & (3) & $(4)$ & (5) & $(6)$ \\
\hline & Nom & Nom & Nom & Elec & Elec & Elec \\
\hline $\begin{array}{c}\text { Number of } \\
\text { politicians }\end{array}$ & $\begin{array}{c}0.022 \\
(0.012)\end{array}$ & $\begin{array}{c}0.024 \\
(0.012)\end{array}$ & $\begin{array}{c}0.024 \\
(0.012)\end{array}$ & $\begin{array}{c}0.001 \\
(0.005)\end{array}$ & $\begin{array}{c}0.003 \\
(0.005)\end{array}$ & $\begin{array}{c}0.003 \\
(0.005)\end{array}$ \\
\hline $\begin{array}{l}\text { Mean } \\
\text { dep.var. }\end{array}$ & 0.615 & 0.610 & 0.615 & 0.114 & 0.113 & 0.114 \\
\hline $\begin{array}{l}\text { Individual } \\
\text { covariates }\end{array}$ & Yes & Yes & Yes & Yes & Yes & Yes \\
\hline $\begin{array}{l}\text { Parent } \\
\text { covariates }\end{array}$ & No & Yes & Yes & No & Yes & Yes \\
\hline Cohort FE & Yes & Yes & Yes & Yes & Yes & Yes \\
\hline Muni. FE & No & No & Yes & No & No & Yes \\
\hline Adjusted $R^{2}$ & 0.003 & 0.003 & 0.004 & 0.001 & 0.001 & 0.001 \\
\hline Observations & $1,226,245$ & $1,122,179$ & $1,099,139$ & $1,226,245$ & $1,122,179$ & $1,099,139$ \\
\hline
\end{tabular}

Note: Results from OLS regressions. The outcome in Columns $1-3$ is running for office at least once in the five elections held between 1998 and 2010 whereas Columns 4-6 instead display results for winning office at least once in the same elections. Standard errors, shown in parentheses, allow for clustering at the school-program level.

three columns repeat the same model specifications as the first three columns, but for another outcome variable. ${ }^{10}$

We begin by discussing the results for voter turnout, in the 2009 European parliament election (Columns 1-3 in Table 2). The effect of the treatment variable is positive, statistically significant, and fairly stable in magnitude across the different specifications. In terms of magnitude, an increase of one politician among the parents of a group of 25 students increases voter turnout by approximately 0.3 percentage points in the 2009 election. Moving to voter turnout in the 2010 general election (Columns 4-6), the coefficient estimates are roughly one-third of the size of the corresponding estimates in the 2009 election, with each additional politician per school class increasing turnout by just above 0.1 percentage points. It is perhaps not surprising that the effects in the 2010 election are much smaller, considering that voter turnout in Swedish general elections in the sample is around $80 \%$. In other words, when most people already participate, there are fewer citizens who potentially can be mobilized. The sample turnout in the European Parliament election is around $40 \%$.

\footnotetext{
${ }^{10}$ We display three specifications for each outcome variable here in the main text for reason of space. In Tables A21-A24 in the Online Appendix, we display additional specifications for transparency.
} 
These mobilizing effects on turnout may appear small. After all, the influence of one more politician parent in a class of 25 students on turnout in the 2009 election is only twice as large as the effect of sending out a mail reminding people to vote in an upcoming election or of sending a prerecorded message to someone's phone (Green et al., 2013), both of which are considered to be ineffective methods for getting out the vote. Nonetheless, one should keep in mind that we measure our outcome variables $0-13$ years after the individual graduated. Thus, the estimates we present in Table 2 provide evidence of the long-term effects of a modest treatment. We return to the question about real-world importance of these effects below.

The other two outcome variables measure much rarer events. In our sample, where a large majority of the individuals are between 18 and 32 years old when we measure the outcomes, only $0.6 \%$ have run for office and slightly more than $0.1 \%$ have ever been elected. Table 3 displays the results for both of these outcomes. The estimated effect of vertical social ties to a politician on the probability of being nominated is positive and statistically significant in all models (Columns 1-3). The magnitude of the effect fluctuates around 0.024, meaning that the probability that an individual is ever nominated to political office increases by 0.024 percentage points for every extra politician among the parents of 25 students. Once again, this may appear as a very small effect. Yet, it corresponds to a four percent increase in the baseline probability of ever running for office $(0.6 \%)$. With regards to the last outcome where we examine individuals being elected to office, the estimated coefficients are positive but smaller in comparison to the estimates for standing as a candidate. The effect is not statistically significant in any of the specifications. Still, because of the low probability of having been elected in this sample of young adults, the relative size of the point estimate in comparison to the mean value of the outcome variable is close to $3 \%$.

\section{Can the Results be Trusted?}

The causal interpretation of the results presented above hinges on the assumption that the year-to-year variation in the share of politicians in a class is "as good as random" conditional on the covariates being included in the model. If this assumption is correct, we should not find any effects if we replace our dependent variables with outcomes that should not be affected by social ties to a politician. For such placebo tests to be convincing, they should focus on variables that are key suspects in a story about selection bias, such as when students select into different treatments based on individual characteristics which are also correlated with political participation.

We regress a set of possible confounders on the treatment variable: (i) standardized grades from the ninth grade of elementary school, (ii) standardized 
test scores for cognitive ability from mandatory conscription, (iii) standardized test scores for non-cognitive ability (social skills) from mandatory conscription, (iv) standardized grades from upper secondary school, (v) the two parents' average turnout in 2009 and 2010 (number of votes out of the possible four, in percent), and (vi) the share of the two parents who ran for office before their child began upper secondary school $(0 \%, 50 \%$, or $100 \%) .{ }^{11}$

Because the cognitive and non-cognitive ability scores are based on tests carried out during military conscription, these variables are primarily available for the male segment of the population. Although cognitive and non-cognitive ability, parental turnout and grades from upper secondary school are measured during or after the treatment, we would not expect social ties to a politician to have a noticeable effect on these outcomes. If we were to find any treatment effects on the placebo outcomes, it would suggest that our identifying assumption does not hold. It is therefore reassuring that all six coefficient estimates in Table 4 are statistically insignificant and small in magnitude in comparison with the mean levels.

The placebo analysis in Table 4 is also related to the above discussion on effect sizes and statistical significance. A potential objection against our main findings is that the estimates are bound to be statistically significant due to the very large sample size at our disposal. Two things should be noted here. First, our identification strategy with fixed effects for school-program categories implies that we only exploit a small fraction of the total variation in the data. Put differently, the effective sample size is much smaller than the just over one million observations in the estimation sample would suggest. Second, as we have already argued, the treatment we employ is very modest and the effect on political participation we study is long-term so we should not expect to find any large effects. What the placebo analysis in Table 4 further tells us is that we do not find any statistically significant effects on the placebo outcomes despite the sample size used.

An alternative means to check the reasonableness of our empirical specification is to add various types of time trends to the model specification. If the results are driven by changes in the quality of schools and programs over time, rather than by the observed number of politicians, the effect should disappear once time trends are included in the specification. Table 5 presents the results from a set of models that are based on the same covariates as the models in Columns 3 and 6 in Tables 2 and 3, but which also include separate time trends for each combination of school and program.

Although there is a slight decrease in the coefficients for voter turnout when adding school-program trends to the models, the overall pattern of results remains intact. Tables A1 and A2 in the Online Appendix further show that

\footnotetext{
${ }^{11}$ We have also analyzed parental turnout in 2009 and 2010 separately, and the share of the two parents who had been elected before their kid began upper secondary school. We find no statistically significant effects on any of these placebo outcomes.
} 
Table 4: Placebo analysis.

\begin{tabular}{|c|c|c|c|c|c|c|}
\hline & (1) & (2) & (3) & (4) & (5) & (6) \\
\hline & GradesC & Cog.Abi. & NCog.Abi & GradesU & P.Turnout & P.Nomin. \\
\hline $\begin{array}{l}\text { Number of } \\
\text { politicians }\end{array}$ & $\begin{array}{c}0.001 \\
(0.001)\end{array}$ & $\begin{array}{c}0.000 \\
(0.004)\end{array}$ & $\begin{array}{l}-0.000 \\
(0.005)\end{array}$ & $\begin{array}{l}-0.004 \\
(0.010)\end{array}$ & $\begin{array}{c}0.049 \\
(0.036)\end{array}$ & $\begin{array}{c}0.011 \\
(0.016)\end{array}$ \\
\hline $\begin{array}{l}\text { Mean } \\
\text { dep.var. }\end{array}$ & 0.013 & 5.153 & 5.006 & 12.174 & 66.064 & 1.643 \\
\hline $\begin{array}{l}\text { Individual } \\
\text { covariates }\end{array}$ & Yes & Yes & Yes & Yes & Yes & Yes \\
\hline $\begin{array}{l}\text { Parent } \\
\text { covariates }\end{array}$ & Yes & Yes & Yes & Yes & Yes & Yes \\
\hline Cohort FE & Yes & Yes & Yes & Yes & Yes & Yes \\
\hline Muni. FE & Yes & Yes & Yes & Yes & Yes & Yes \\
\hline Adjusted $R^{2}$ & 0.460 & 0.349 & 0.123 & 0.225 & 0.198 & 0.015 \\
\hline Observations & $1,091,970$ & 330,931 & 268,511 & 990,553 & $1,099,139$ & $1,099,139$ \\
\hline
\end{tabular}

Note: Results from OLS regressions. The dependent variables, from left to right, measure standardized grades from compulsory school (Column 1), standardized test scores for cognitive ability from conscription (Column 2), non-cognitive ability from conscription (Column 3), standardized test scores from upper secondary school (Column 4), the parents' average turnout in 2009 and 2010 (Column 5) and the share of the parents who ran for office before their child began upper secondary school (Column 6). Standard errors, shown in parentheses, allow for clustering at the school-program level.

Table 5: School-program-specific time trends.

\begin{tabular}{lcccc}
\hline & $(1)$ & $(2)$ & $(3)$ & $(4)$ \\
& Vote09 & Vote10 & Nom & Elec \\
\hline Number of politicians & 0.262 & 0.072 & 0.025 & 0.003 \\
& $(0.074)$ & $(0.055)$ & $(0.013)$ & $(0.006)$ \\
\hline Mean dep.var. & 40.815 & 81.256 & 0.615 & 0.114 \\
Individual covariates & Yes & Yes & Yes & Yes \\
Parent covariates & Yes & Yes & Yes & Yes \\
Cohort FE & Yes & Yes & Yes & Yes \\
Muni. FE & Yes & Yes & Yes & Yes \\
School-program trend & Yes & Yes & Yes & Yes \\
Adjusted $R^{2}$ & 0.115 & 0.133 & 0.001 & -0.002 \\
Observations & 909,690 & $1,091,336$ & $1,099,139$ & $1,099,139$ \\
\hline
\end{tabular}

Note: Results from OLS regressions. The dependent variables, from left to right, measure turnout in the $2009 \mathrm{EP}$ election (Column 1), turnout in the 2010 national election (Column 2), running for office at least once in the five elections held between 1998 and 2010 (Column 3), and winning office at least once in the same elections (Column 4). Standard errors, shown in parentheses, allow for clustering at the school-program level. 
we obtain very similar results if we also include separate trends for schools and programs or if we control for politician parents in the classes preceding and succeeding the treated classes in question. Together, these analyses suggest that the results do not appear to be driven by trends at the school-program level. ${ }^{12}$

Another important issue concerns the time horizon of our analysis. We previously argued that the results displayed in Tables 2 and 3 should be interpreted as the long-term impact of social connections to politicians because our sample includes individuals who graduated $0-13$ years before their political engagement is measured. To further examine this, Tables A10 and A11 in the Online Appendix present estimates from models in which the treatment indicator is interacted with an indicator for the number of years since graduation. The results support our interpretation of long-term positive treatment effects. The conditional treatment effects across years since graduation among the young adults are well in line with political socialization research showing that parental influence on political engagement diminishes as a consequence of individuals leaving the parental home in their early twenties and increasingly coming under the influence of other networks (Bhatti and Hansen, 2012; Gidengil et al., 2016).

Throughout the paper, we assume a linear relationship between the number of politicians and our different outcomes. In Tables A3 and A4 in the Online Appendix, we present results where we experiment with other functional forms. The general conclusion is that the linear model is a decent approximation, but that it also hides some important nuances. For example, we find that the marginal effect of an additional politician is decreasing for low-demanding activities as voting in the national election, and increasing for the rare event of running for political office. The latter results appear somewhat more sensitive to the functional form assumption, which suggest that we should interpret the political candidacy results with some extra caution.

We have run several additional robustness checks that we present in the Online Appendix. We show that: (i) we obtain very similar estimated marginal effects when using a logit estimator (Table A5); (ii) our results are not sensitive to outliers in terms of classes with a very high share of politician parents or classes with a very small or large number of students (Figures A1 and A2, Tables A6 and A7); and (iii) the results are similar when we change the treatment to elected politician parents instead of nominated parents (Tables A8 and A9). Together, these robustness checks further strengthen our confidence in the internal validity of the results.

\footnotetext{
${ }^{12}$ The estimations with trends are carried out by the Stata package reghdfe developed by Correia (2014).
} 


\section{What Drives the Results?}

A natural follow-up question would address the possible mechanisms that underlie the observed reduced form effects presented in the last section. Although the data used in this study enables stringent tests of the overall impact of vertical social ties on political participation, it is less apt for directly studying different causal mechanisms because we do not have information on how and with whom a person spent time during upper secondary school. We may however indirectly address this important issue by employing the register data that we have used so far and additional survey data presented below.

As discussed in the theory section, one important question concerns the exact pathway behind the influence of politician parents: should the observed effect be interpreted as a direct effect of having been in proximity to the politician parent or as an indirect effect mediated by the child of the politician? It could also be that non-politician parents during upper secondary school become interested in politics and eventually run for office in the future after the child has finished upper secondary school because there is a politician parent in their child's class. The mechanism in this case would be an intergenerational transmission taking place after upper secondary school that was initialized by another parent. Another, albeit less likely, mechanism is that the non-politician parent becomes interested in politics and eventually runs for office and the effect is mediated by the children of politician parents. We illustrate these different mechanism pathways in Figure 4.

We address this question by creating two separate treatment variables: one where we only include politicians whose children voted in the 2009 European parliament election, and one where we only include those with children who abstained. The logic underlying this model specification is the following: if the overall treatment effect is mainly explained by direct links to the politician parent, it should not matter if his or her child is politically active or not. If, on the other hand, the influence of vertical social ties is mediated by the child of the politician, we should expect the treatment effect to be weaker if the child is politically inactive (as proxied by not having voted in the EP election as an adult).

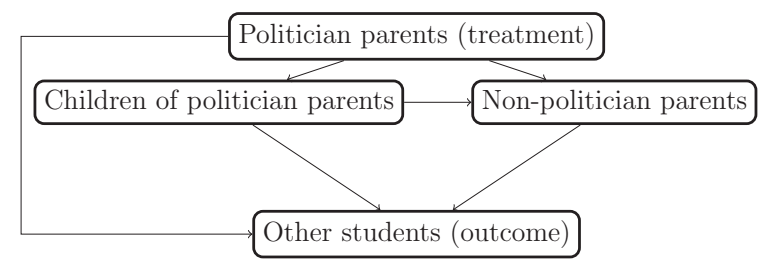

Figure 4: Mechanisms channels. 
Another important mechanism question also remains to be discussed. Do the main results reflect a treatment effect that only materializes when there is an active politician among the parents in the class during upper secondary school? Or, rather, is the treatment a proxy for being enrolled in a class with parents who are politically interested and engaged in general, but who do not necessarily stand as a candidate during the time his or her child attends upper secondary school? If those parents who run for political office at some point in life carry traits that differ from those who never run for office, and if these traits are also more likely to be carried by the children of these parents, then the politically active parents may be influencing students' future political behavior even if they do not run for office when their children are in uppersecondary school. One way of separating between these two possibilities is to estimate models in which we include a treatment variable that measures the number of politicians who run for office before or after the children attended upper secondary school. If the impact of vertical political ties reflects an effect of having classmates whose parents are politically interested and engaged in general, it should matter less when the politician runs for office. If we instead believe that the treatment effect is driven by the politician parent acting as a candidate, the estimated effects should be much weaker for the variable that measures the number of politicians running for office before or after their children attended upper secondary school.

We present some of the mechanism results here in the main text and some in the appendix. In Table A12, we show that parents who were not politicians during upper secondary school are not more likely to become politicians later on because politician parents were in the class. We also do not find any evidence that non-politician parents are affected by having a child in the class where students of politician parents are politically interested (proxied by voting in the $2009 \mathrm{EP}$ election). We thus rule out an intergeneratonal mechanism taking place after upper secondary school (the right-hand channels in Figure 4).

In the main text we focus instead on whether the effect is mediated by the students in the class (the left-hand channels in Figure 4) and the timing of the treatment. The empirical results of both of these mechanism tests are presented in Table 6. To begin with the question of whether the effect is direct or mediated by the student, the results presented in Columns 1-4 in Table 6 are very much in line with the second interpretation. Table 6 splits our main treatment variable into two. The first row in Columns 1-4 displays the estimated coefficients for the number of politicians among the students who voted in the $2009 \mathrm{EP}$ election. The second row displays the equivalent estimated coefficient for the number of politician parents among the students who did not vote in the 2009 election. We estimate positive and statistically significant effects for the first variable and very small and statistically insignificant coefficients for the second. These results suggest that 


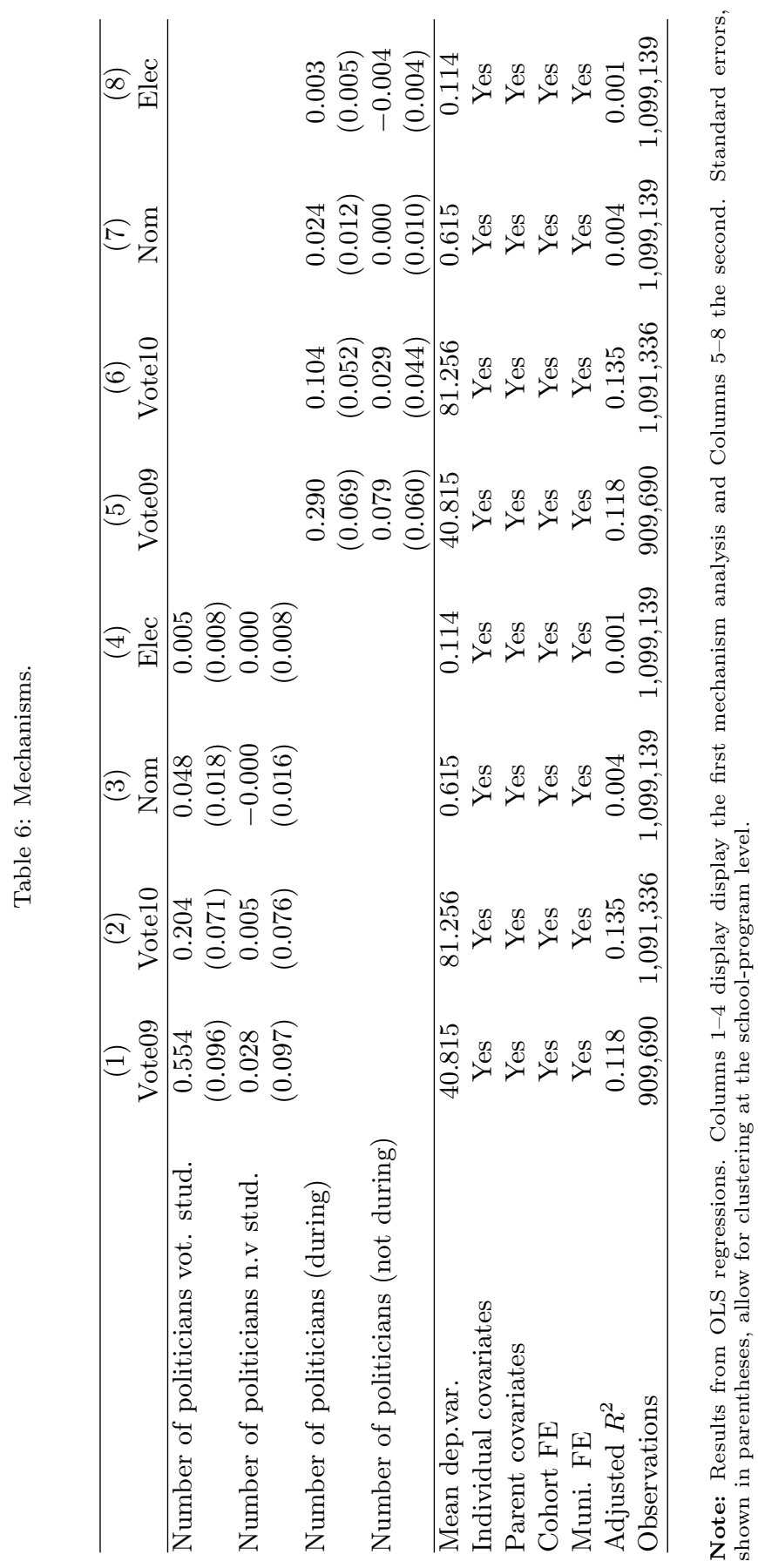


the effect appears to be mediated by the children of politicians. Thus, our results imply that the effect of vertical social ties to a politician is not direct.

Turning to the question of whether the treatment effect is driven by having a parent who is running for office during upper secondary school or whether it captures the effect of having a politically interested parent in the class, the empirical results point towards the first explanation. The estimated coefficients for having ever run for office, but not during the time when the child attended upper secondary school, is much smaller than the main estimated effect (Columns 5-8 in Table 6).

The analyses presented above suggest that the effect of having a classmate whose parent is a politician is mediated via the child of the politician and that the mediated effect hinges on the parent running for office during upper secondary school, a period in life often referred to as the impressionable years in the earlier literature.

However, as discussed in the theory section, we should also direct our attention to different intermediary causal mechanisms such as civic skills, psychological engagement, and recruitment activities (Verba et al., 1995). In the Online Appendix, we present results from two sets of analyses intended to investigate two of these mechanisms. First, we run a number of separate party-specific models in which we employ two treatments - the number of politician parents running for a certain party (e.g., the Social Democrats) and the number of politicians running for other parties - and where the outcome is running for the same party among the children. The idea here is to test whether the estimated treatment effect for elite political participation in Table 3 in the previous section reflects a general increase in political participation, or if the effect instead signals partisan recruitment efforts. Most of the estimates in these tables (Tables A13-A19 in the Online Appendix) are small in magnitude and statistically insignificant. The overall conclusion is that the effect seems to be due to a general increase in the probability of running for office, rather than due to partisan recruitment.

Finally, we make use of additional data from Statistics Sweden in order to test whether vertical social ties influence individuals' political interest as measured by their willingness to take part in political discussions. The information on political discussions is obtained from the yearly Living Conditions Surveys (ULF/SILC) carried out by Statistics Sweden since 1980. We merged the respondents in all waves of ULF/SILC from 1997 and onward to our data. Although the sample size of this survey is fairly large - approximately 6,000 respondents in each wave - we are left with an estimation sample that is several orders of magnitude smaller than the sample we use in the main analysis. The estimated effects of our treatment variable on an individual's self-reported willingness to take part in political discussions are presented in Table A20. As expected, the estimates are rather imprecise and do not reach conventional levels of significance. Nevertheless, the effects in all specifications 
are positive, implying that vertical social ties to politicians during upper secondary school may have lasting effects on individuals' political interest with possible downstream effects on actual political participation.

\section{Who is Mobilized?}

So far, we have presented robust evidence that students who are exposed to active politicians during adolescence are on average more politically active later in life than similar students who do not receive such exposure. We have also explored some of the mechanisms and pathways mediating this treatment effect. Average effects of this type, however, may conceal as much as they reveal. In this section, we go one step further to investigate whether the mobilization effect is stronger for some groups than for others.

We previously argued that there are reasons to expect the mobilization pattern to vary across different types of political participation. Specifically, we hypothesized that for rare political activities, such as running for office, political ties should mainly affect individuals with a fairly high predisposition to engage in politics, whereas the opposite should be true for political activities that most people perform, such as voting in national elections.

To assess if the mobilizing effect of social ties to a politician is conditional on the individual's underlying tendency to participate - and if there are different patterns of heterogeneity for different political acts - we constructed measures of what we refer to as a person's "nascent political activity" (NPA). Inspired by Fox and Lawless (2005), these indicators are measured as the predicted propensities to vote in the 2009 European Union parliament election and the 2010 Swedish general elections, run for office and get elected, respectively, based on regressions of each of the four outcomes on a large set of variables which are predominantly measured before the child starts secondary school. More specifically, we run regressions for each outcome variable and include as regressors gender, GPA from ninth grade, and for each parent: four binary indicators of his or her political participation (ever nominated before the child turned 16, ever elected before the child turned 16, voted in 2009 and voted in 2010) and five socioeconomic indicators (age, social assistance recipient status, employment status, years of education and income standardized within year). We then predict the outcomes based on these variables and refer to these predictions as NPA.

Figure 5 displays the distribution of these measures in the population under study. As expected, there are large differences in the distribution of nascent political activity across different participatory acts. We find that most individuals have very low propensities to run for office or become elected, as indicated by the two lower subgraphs. However, the results also demonstrate that a majority of the individuals are instead very likely to vote in the national 


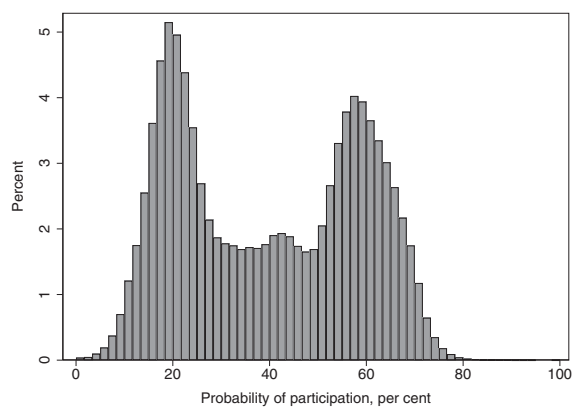

(a)

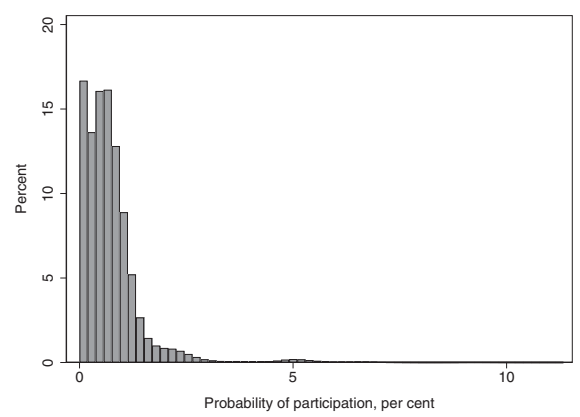

(c)

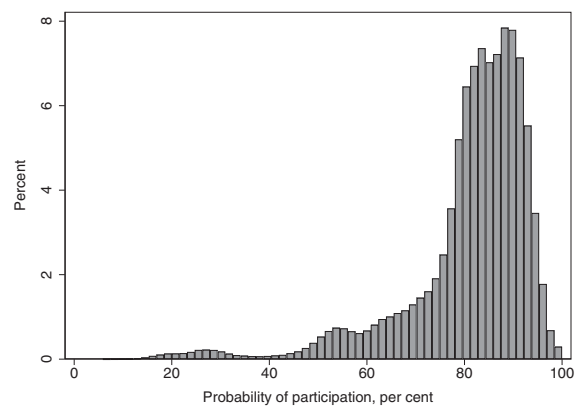

(b)

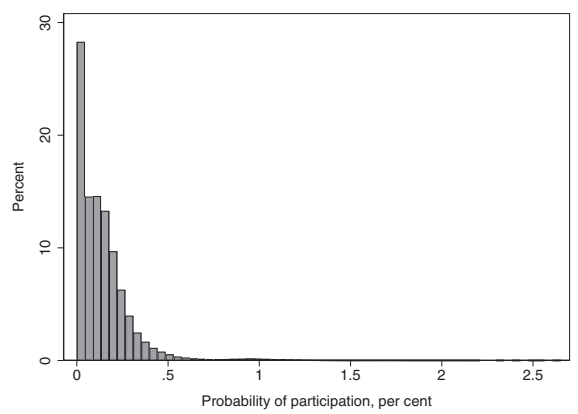

(d)

Figure 5: Distribution of nascent political activity. (a) Voting in 2009. (b) Voting in 2010. (c) Ever nominated. (d) Ever elected.

election (Figure 5(a)). The distribution of vote propensities in the European parliament election (Figure 5(b)) fall in between these two extremes. It has a bimodal shape with the first hump around $20 \%$ and the second around $60 \%$. The properties of these distributions reflect that the parent's political participation is a very strong predictor of their children's political ambition, and the two parents' binary participatory indicators can only be combined in four different ways.

We investigate how the effect of vertical social ties to politicians depends on an individual's basic predisposition to engage in a particular political act using flexible interaction models, in which our treatment variable is interacted with a set of cubic splines for our measures of nascent political activity, but otherwise use the model specifications from Column 3 in Tables 2 and $3{ }^{13}$

\footnotetext{
${ }^{13}$ We use restricted cubic splines with five knots that are placed at the following percentiles of the underlying variable: 5, 27.5, 50, 72.5, and 95. In Figure A4 in the Online Appendix, we display similar results for an alternative approach for estimating potentially heterogeneous effects with respect to NPA.
} 


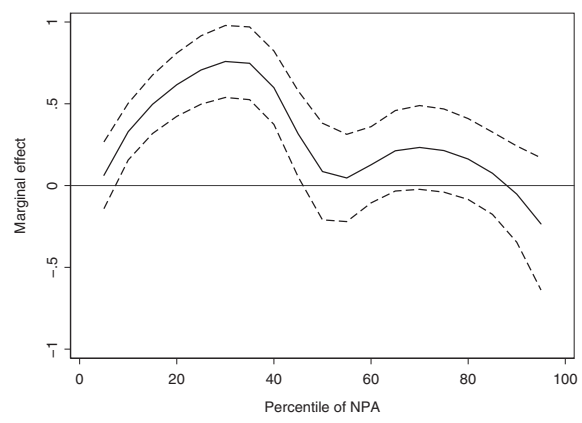

(a)

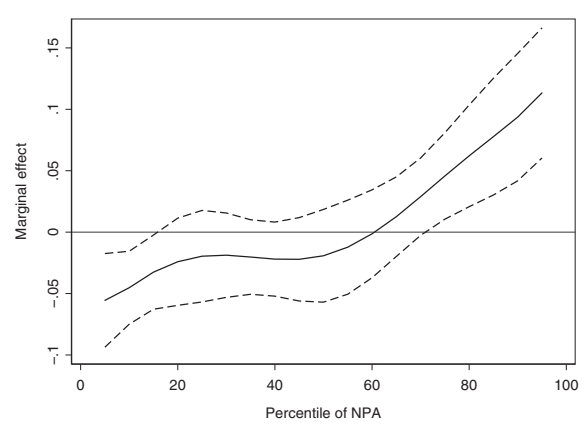

(c)

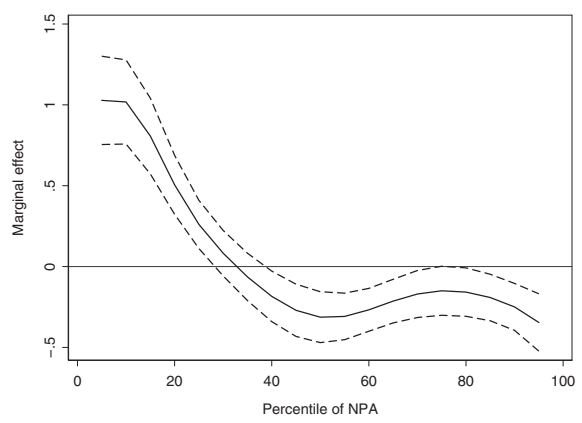

(b)

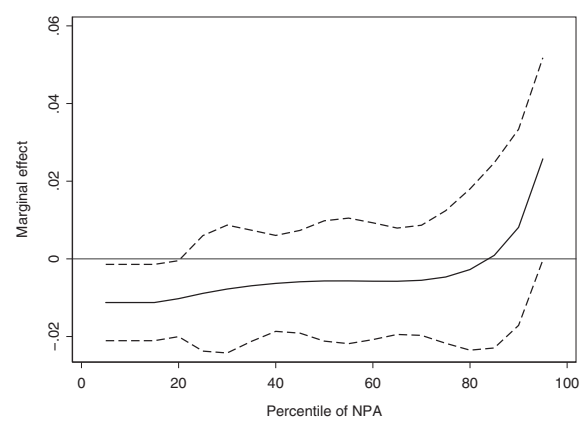

(d)

Figure 6: Marginal effects by political act and nascent political activity (NPA). (a) Voting in 2009. (b) Voting in 2010. (c) Ever nominated. (d) Ever elected.

For ease of interpretation we present the results graphically in Figure 6. The solid lines denote the marginal effects of adding one extra parent politician in a class at various percentiles of nascent political activity, and the dashed lines represent $95 \%$ confidence intervals for these effects.

Overall, the patterns in the different subgraphs are in line with our expectations. With respect to the two measures of elite political participation we see that the marginal treatment effect is increasing in NPA. Whereas the effect on winning political office (Figure 6(d)) never reaches conventional levels of statistical significance, the positive effect previously found for candidacy is now shown to be driven by the mobilization of individuals scoring in the top third of the NPA distribution (see Figure 6(c)). For voting in the national election (Figure 6(b)), we instead find the opposite pattern. Here, the marginal effects are decreasing in NPA and the positive average effect is entirely due to mobilization in the bottom third of the NPA distribution. The results with respect to the European parliament (Figure 6(a)) election are a bit less 
clear-cut in that the marginal effects display a non-linear pattern over NPA. With that being said, however, we only find statistically significant effects of social ties to politicians on voting in the 2009 EP election in the lower half of the NPA distribution.

The results in Figure 6 thus lend support to the view that social ties to politicians may serve to mobilize different types of individuals depending on the nature of the political act in question. Somewhat simplified, the results indicate that for elite participation, vertical social ties only matter for individuals from affluent and politicized family backgrounds, whereas the same connections primarily matter for individuals from less politically privileged backgrounds when it comes to voting.

\section{Conclusion}

Politics and political action need to be understood as social phenomena (Zuckerman, 2005). In particular, it is important to consider that decisions to engage in politics are always taken in a social context. Our choices are simply not made in a vacuum, separately from other people. Against this backdrop, our study focuses on the long-term effects of weak social ties to active politicians on political participation. Using detailed population-wide individual-level administrative data from Sweden, we provide new evidence on the impact of having connections to politicians during adolescence on voter turnout and the likelihood of running for and winning political office as adults. We find that students who attend classes with a larger number of politically active parents are more politically active as adults. Such individuals are found to be more likely to vote in elections and to run for office in adulthood. This positive influence of social ties to active politicians appears to be mediated by indirect links between the politician and the individual via the politician's child. Furthermore, the results suggest that the strength of these mobilizing effects depends on the individual's basic predisposition to engage in the political act in question.

Our study makes several important contributions. Above all, as far as we know, it is the first study to provide evidence of a causal effect of weak vertical social ties on political participation. We document these effects both for mass and, somewhat less precise, for elite participation. As such, our results provide a valuable complement to previous studies on the social logic of political participation that predominantly focus on the effects of strong horizontal social ties on political attitudes and behavior at the mass level using research designs that, with a few notable exceptions (Bhatti et al., 2014; Nickerson, 2008), are correlational in nature (Huckfeldt and Sprague, 1995; Kenny, 1992; La Due Lake and Huckfeldt, 1998; McClurg, 2003; Mutz, 2002). 
A potential objection one may raise to our study is the limited real world importance of our findings. The effect sizes we find may, by some, be considered small. We would, however, argue that such quarrels are somewhat misapplied. In the results section, we argued that one needs to take into account both the modest nature of our treatment and the fact that we measure our outcomes up to 13 years after the individuals graduated from upper secondary school when assessing the magnitude of the estimated effects.

Moreover, during their lifetime, most citizens interact with a very large number of people. It is thus not difficult to imagine how all of those interactions may sum up to decisively shape the political behavior of an individual. Understanding how individuals' behavioral tendencies in the political sphere are shaped and molded by different social relations should be a key concern for political science research. Our study is one of the first to provide compelling causal evidence that not only strong social ties, but also weaker ones, can influence individual's political behavior. In this sense, we consider our work as a small but important step towards a fuller account of how we function as political beings. Relatedly, it should also be remembered that our results indicate that there is a fair degree of variation in the magnitude of these effects across different subgroups of the population, which means that the effect sizes can be quite substantial for individuals from certain groups.

This last point is also important insofar as it speaks directly to the question of the distribution of political power. Scholarly interest in political participation often stems from a deeper concern about political inequality. Because participation tends to be more unequal when the number of participants is small, increased participation is often put forward as a remedy to this problem (Lijphart, 1997). However, this does not imply that every measure which stimulates political participation is beneficial for political equality. The results of this study clearly illustrate this point. Reforms aimed at increasing the share of individuals with social ties to political representatives seem to be somewhat of a double-edged sword in the sense that they may either serve to decrease or increase inequality depending on the nature of the political act in question. Consequently, whereas Dahl and Tufte (1973) are correct in assuming that political participation is higher in smaller political units because individual citizens are more likely to be acquainted with their political representatives, this does not necessarily make small units more politically equal.

Our results do, however, suggest that a more equal distribution of social ties to politically active citizens and politicians could help to reduce overall political inequality in society. Today, better off children are considerably more likely to be surrounded by politically engaged adults both in their close and more distant social networks compared to their less fortunate peers, which makes them more likely to become politically active themselves as adults. Inequalities with respect to the more distant network (the weak ties) is to a 
large extent the result of school and residential segregation. An important lesson from this study is that enacting policies aimed at reducing segregation and promoting the diversity of youth networks can be an important means of alleviating the political inequality that haunts many democratic countries.

\section{References}

Bäck, H. 2003. "Explaining and Predicting Coalition Outcomes". European Journal of Political Research 42(4): 441-72.

Barreto, M. A. 2007. "İ Sí Se Puede! Latino Candidates and the Mobilization of Latino Voters". American Political Science Review 101(3): 425-41.

Barreto, M. A. and S. A. Nuño. 2011. "The Effectiveness of Coethnic Contact on Latino Political Recruitment". Political Research Quarterly 64(2): 44859.

Beck, P. A. and M. K. Jennings. 1982. "Pathways to Participation". American Political Science Review 76(1): 94-108.

Berndt, T. J., A. E. Laychak, and K. Park. 1990. "Friends' Influence on Adolescents' Academic Achievement Motivation: An Experimental Study". Journal of Educational Psychology 82(4): 664-70.

Bhatti, Y., J. O. Dahlgaard, J. Hansen, and K. M. Hansen. 2014. "How Voter Mobilization Spread in Households and Families - The Use of Short Text Messages on Cell Phones to Boost Turnout". APSA 2014 Annual Meeting Paper. Available at SSRN (2452594). https://papers.ssrn.com/sol3/papers. cfm?abstract_id $=2452594$.

Bhatti, Y. and K. M. Hansen. 2012. "Leaving the Nest and the Social Act of Voting: Turnout among First-Time Voters". Journal of Elections, Public Opinion and Parties 22(4): 380-406.

Bhatti, Y., K. M. Hansen, and H. Wass. 2012. "The Relationship Between Age and Turnout: A Roller-Coaster Ride". Electoral Studies 31(3): 588-93.

Campbell, D. E. 2008. "Voice in the Classroom: How an Open Classroom Climate Fosters Political Engagement Among Adolescents". Political Behavior 30(4): 437-54.

Campbell, D. E. 2013. "Social Networks and Political Participation". Annual Review of Political Science 16(1): 33-48.

Campbell, D. E. and C. Wolbrecht. 2006. "See Jane Run: Women Politicians as Role Models for Adolescents". Journal of Politics 68(2): 233-47.

Cesarini, D., M. Johannesson, and S. Oskarsson. 2014. "Pre-birth Factors, Post-birth Factors, and Voting: Evidence from Swedish Adoption Data". American Political Science Review 108(1): 71-87.

Cherng, H.-Y. S., J. M. Calarco, and G. Kao. 2013. "Along for the Ride: Best Friends' Resources and Adolescents' College Completion". American Educational Research Journal 50(1): 76-106. 
Choi, K. H., R. Kelly Raley, C. Muller, and C. Riegle-Crumb. 2008. "Class Composition: Socioeconomic Characteristics of Coursemates and College Enrollment". Social Science Quarterly 89(4): 846-66.

Correia, S. 2014. REGHDFE: Stata Module to Perform Linear or InstrumentalVariable Regression Absorbing Any Number of High-dimensional Fixed Effects. Statistical Software Components, Boston College Department of Economics.

Dahl, R. A. and E. R. Tufte. 1973. Size and Democracy. Vol. 2. Stanford University Press.

Dawes, C., D. Cesarini, J. H. Fowler, M. Johannesson, P. K. Magnusson, and S. Oskarsson. 2014. "The Relationship between Genes, Psychological Traits, and Political Participation". American Journal of Political Science 58(4): 888-903.

Fowler, J. H., L. A. Baker, and C. T. Dawes. 2008. "Genetic Variation in Political Participation". American Political Science Review 102(2): 233-48.

Fox, R. L. and J. L. Lawless. 2005. "To Run or Not to Run for Office: Explaining Nascent Political Ambition". American Journal of Political Science 49(3): $642-59$.

Gidengil, E., H. Wass, and M. Valaste. 2016. "Political Socialization and Voting: The Parent-Child Link in Turnout". Political Research Quarterly 69(2): 373-83.

Gilardi, F. 2015. "The Temporary Importance of Role Models for Women's Political Representation". American Journal of Political Science 59(4): 957-70.

Granovetter, M. S. 1973. "The Strength of Weak Ties". American Journal of Sociology 78(6): 1360-80.

Green, D. P., M. C. McGrath, and P. M. Aronow. 2013. "Field Experiments and the Study of Voter Turnout". Journal of Elections, Public Opinion 83 Parties 23(1): 27-48.

Hanks, M. 1981. "Youth, Voluntary Associations and Political Socialization". Social Forces 60(1): 211-23.

Huckfeldt, R. R. and J. Sprague. 1995. Citizens, Politics and Social Communication: Information and Influence in an Election Campaign. Cambridge University Press.

Jennings, M. K. 2007. "Political Socialization". In: The Oxford Handbook of Political Behavior. Ed. R. J. Dalton and H.-D. Klingemann. Oxford: Oxford University Press, 29-44.

Kenny, C. B. 1992. "Political Participation and Effects from the Social Environment". American Journal of Political Science 36(1): 259-67.

Klofstad, C. A. 2007. "Talk Leads to Recruitment". Political Research Quarterly 60(2): 180-91.

Kudrnáč, A. and P. Lyons. 2017. "Parental Example as a Motivation for Turnout among Youths". Political Studies 65(1): 43-63. 
La Due Lake, R. and R. Huckfeldt. 1998. "Social Capital, Social Networks, and Political Participation". Political Psychology 19(3): 567-84.

Lassen, D. D. and S. Serritzlew. 2011. "Size and Equal Opportunity in the Democratic Process: The Effect of the Danish Local Government Reform on Inequality in Internal Political Efficacy". World Political Science Review $7(1): 1-15$.

Lawless, J. L. 2011. Becoming a Candidate. Cambridge University Press.

Lazarsfeld, P. F., B. Berelson, and H. Gaudet. 1944. The People's Choice: How the Voter Makes Up His Mind in a Presidential Campaign. Duell, Sloan, and Pearce.

Lijphart, A. 1997. "Unequal Participation: Democracy's Unresolved Dilemma". American Political Science Review 91(1): 1-14.

Lindgren, K.-O., S. Oskarsson, and M. Persson. 2019. "Enhancing Electoral Equality: Can Education Compensate for Family Background Differences in Voting Participation?" American Political Science Review 113(1): 108-22.

McClurg, S. D. 2003. "Social Networks and Political Participation: The Role of Social Interaction in Explaining Political Participation". Political Research Quarterly 56(4): 449-64.

McConnaughy, C. M., I. K. White, D. L. Leal, and J. P. Casellas. 2010. "A Latino on the Ballot: Explaining Coethnic Voting Among Latinos and the Response of White Americans". The Journal of Politics 72(4): 1199-211.

McFarland, D. A. and R. J. Thomas. 2006. "Bowling Young: How Youth Voluntary Associations Influence Adult Political Participation". American Sociological Review 71(3): 401-25.

Mutz, D. C. 2002. "The Consequences of Cross-Cutting Networks for Political Participation". American Journal of Political Science 46(4): 838-55.

Neundorf, A. and K. Smets. 2017. Political Socialization and the Making of Citizens. en. Vol. 1. Oxford University Press.

Nickerson, D. W. 2008. "Is Voting Contagious? Evidence from Two Field Experiments". American Political Science Review 102(1): 49-57.

Ocampo, A. X. 2018. "The Politics of Inclusion: A Sense of Belonging to US Society and Latino Political Participation". PhD thesis. Los Angeles: University of California.

Oskarsson, S., C. T. Dawes, and K.-O. Lindgren. 2018. "It Runs in the Family. A Study of Political Candidacy Among Swedish Adoptees". Political Behavior 40(4): 883-908.

Putnam, R. D. 2000. Bowling Alone: The Collapse and Revival of American Community. Simon \& Schuster.

Putnam, R. D. 2015. Our Kids: The American Dream in Crisis. Simon \& Schuster.

Putnam, R. D., R. Leonardi, and R. Nanetti. 1993. Making Democracy Work: Civic Traditions in Modern Italy. Princeton paperbacks. Princeton University Press. 
Robnett, R. D. and C. Leaper. 2013. "Friendship Groups, Personal Motivation, and Gender in Relation to High School Students' STEM Career Interest". Journal of Research on Adolescence 23(4): 652-64.

Rolfe, M. 2012. Voter Turnout: A Social Theory of Political Participation. Cambridge books online. Cambridge University Press.

Rubin, K. H., W. M. Bukowski, J. G. Parker, and J. C. Bowker. 2008. "Peer interactions, relationships, and groups". In: Child and adolescent development: An advanced course. Ed. W. Damon, R. M. Lerner, D. Kuhn, R. S. Siegler, and N. Eisenberg. John Wiley \& Sons, Inc., 141-80.

Ryan, A. M. 2000. "Peer Groups as a Context for the Socialization of Adolescents' Motivation, Engagement, and Achievement in School". Educational Psychologist 35(2): 101-11.

SCB. 2018. "Hur gick det för eleverna som var obehöriga till gymnasieskolan?". Temarapport. Available at: https://www.scb.se/hitta-statistik/statistikefter-amne/utbildning-och-forskning/befolkningens-utbildning/analyseroch - statistik - om - befolkningens - utbildning / pong / publikationer / hur gick-det-for-eleverna-som-var-obehoriga-till-gymnasieskolan/. Accessed 2020-01-21.

Shah, P. 2014. "It Takes a Black Candidate: A Supply-side Theory of Minority Representation". Political Research Quarterly 67(2): 266-79.

Smith, A. E. 2016. "People Who Know People: Vertical Social Ties and Campaign Participation in Unequal Contexts". Unpublished manuscript. Available at SSRN (2704924). https://papers.ssrn.com/sol3/papers.cfm? abstract id $=2704924$.

Smith, E. S. 1999. "The Effects of Investments in the Social Capital of Youth on Political and Civic Behavior in Young Adulthood: A Longitudinal Analysis". Political psychology 20(3): 553-80.

Stoker, L. and J. Bass. 2011. "Political Socialization". In: The Oxford Handbook of American Public Opinion and the Media. Ed. R. Y. Shapiro and L. R. Jacobs. Oxford: Oxford University Press.

Teorell, J. 2003. "Linking Social Capital to Political Participation: Voluntary Associations and Networks of Recruitment in Sweden". Scandinavian Political Studies 26(1): 49-66.

Verba, S., K. L. Schlozman, and H. E. Brady. 1995. Voice and Equality: Civic Voluntarism in American Politics. Harvard University Press.

Wolbrecht, C. and D. E. Campbell. 2007. "Leading by Example: Female Members of Parliament as Political Role Models". American Journal of Political Science 51(4): 921-39.

Zuckerman, A. S. 2005. The Social Logic of Politics: Personal Networks as Contexts for Political Behavior. Temple University Press. 